\section{Intervenção \\ Psicossocial em um Centro de Acolhida Especial para Mulheres em São Paulo}

\section{Psychosocial Interventions in a Shelter Centre for Women in São Paulo}

\section{Resumo}

A intervenção psicossocial (2018) centrou-se na qualidade das relações interpessoais dos funcionários e equipe técnica de um centro de acolhida para mulheres em vulnerabilidade social (CAE) e visou promover a conscientização da potencialidade de cada funcionário, reforçando seus pontos fortes, reconhecendo seus pontos fracos e, a partir disso, desenvolver uma reflexão acerca de como melhorar, por meio de ações concretas, seu desempenho dentro da instituição, estabelecendo a compreensão das delimitações de suas funções. O objetivo geral da proposta foi compreender as inter-relações de trabalho dentro do CAE e analisar como a subjetividade de cada funcionário influencia o funcionamento da instituição. Constou de um estudo de caso, uma atuação em campo, com caráter exploratório e características qualitativas de análise. As técnicas foram observacionais, entrevistas individuais e dinâmicas em grupo. Os resultados da pesquisa mostraram que os funcionários estão divididos, uns não aceitam a atual gestão e os demais por serem novatos ou indicados pela atual gestão, identificam-se com as novas propostas e estão mais satisfeitos. A intervenção buscou por meio da reflexão dos funcionários, evitar as contradições, em prol da coesão e do ambiente de trabalho mais saudável.
Prof. ${ }^{a}$ Dr. ${ }^{a}$ Esther

Cabado Modia

Doutora em Psicologia Social pela Universidade de São Paulo (USP). Docente e supervisora de estágio na Universidade Cruzeiro do Sul, no curso de Psicologia. Professora titular da Universidade Paulista (Unip), no curso de Administração.

E-mail: ecmodia@alumni. usp.br

Raianny Martins Santos

Graduanda do décimo semestre em Psicologia, Universidade Cruzeiro do Sul

E-mail:raianny.martins@ hotmail.com

\section{Amanda Morais}

Pereira da Silva

Graduanda do décimo semestre em Psicologia, Universidade Cruzeiro do Sul

E-mail: amandammpe@ gmail.com 
Palavras-chave: Centro de acolhida. Psicologia do trabalho. Funcionários. Potencialidades. Agentes sociais. Instituição.

\section{Abstract}

Focusing on the laborers' and technicians' staff, the psycho-social intervention project aimed to promote an awareness of the self potential of each individual worker, reinforcing their strengths and recognizing their weaknesses and, by that, promote a reflection about the means of improving, by concrete actions, their effectiveness in the institution, establishing the delimitations of their own functions. The project was held in a Shelter Center for Women - Centro de Acolhida Especial para Mulheres (CAE) -, in São Paulo. The general target of this study was to understand the interrelations of work inside the CAE and analyze how the subjectivity of each worker influence the operation of the institution. The study consists of a Case Study, exploratory and of qualitative analysis characteristics. The techniques used were observation, interviews and group dynamics. The results of the study show that the workers are divided, some of them accepting the current management and others, being recently arrived or appointed by the management, identify oneself with the new propositions and have more satisfaction. The importance of this intervention was, by an exercise of self reflexion of the workers, to help them in avoiding contradictions in name of a group cohesion and a healthier work space.

Keywords: Shelter Centre. Working psychology. Workers. Potentials. Social Agents. Institution.

\section{Introdução}

A qualidade das relações interpessoais influencia o ambiente como um todo, sendo agregador ou disfuncional. Nesse sentido, realizou-se uma intervenção psicossocial, voltada para a Psicologia do Trabalho, tendo como foco os agentes sociais enquanto elementos fundamentais de investigação. Um Centro de Acolhida Especial para Mulheres (CAE), situado na Zona Leste da
Cidade de São Paulo, permitiu a pesquisa em campo, que se deu em dez visitas, no ano de 2018.

A definição do problema centrou-se na equipe de funcionários e o projeto de intervenção visou promover a conscientização da potencialidade de cada funcionário, reforçando os seus pontos fortes, reconhecendo os seus pontos fracos e, a partir disso, desenvolver uma reflexão acerca de como melhorar, por meio de ações concretas, seu desempenho dentro da instituição e estabelecendo a compreensão das delimitações de suas funções.

A relevância do tema ressaltou-se na possibilidade de conhecer a percepção dos funcionários sobre as atividades desenvolvidas no trabalho, as suas potencialidades e significações sobre pessoas institucionalizadas. Refere-se também à possibilidade de refletir sobre as suas próprias individualidades e descobrir de que forma podem direcionar ações transformacionais, humanas e solidárias, enquanto agentes sociais e, sobretudo, requalificar as relações interpessoais de trabalho.

O objetivo geral da proposta foi compreender as inter-relações de trabalho dentro do CAE e analisar como a subjetividade de cada funcionário influencia o funcionamento da instituição.

O método de procedimentos foi monográfico, um estudo de caso, de caráter exploratório, e com características de análise qualitativa. As técnicas utilizadas foram observacionais, entrevistas individuais e dinâmicas de grupo.

\section{Perspectiva Teórica}

\section{Trabalho e o Capital}

O trabalho, na perspectiva marxista, é definido como uma atividade humana que consiste na alteração do estado natural das coisas. Marx (2011, p. 327) afirma que o trabalho é exclusivo do ser humano, que transforma a natureza a fim de satisfazer as suas necessidades; assim,

O trabalho é, antes de tudo, um processo entre o homem e a natureza, processo este em que o homem, por sua 
própria ação, medeia, regula e controla seu metabolismo com a natureza. A fim de se apropriar da matéria natural de uma forma útil para sua própria vida, ele põe em movimento as forças naturais pertencentes a sua corporeidade: seus braços e pernas, cabeça e mãos. Agindo sobre a natureza externa e modificando-a por meio desse movimento, ele modifica, ao mesmo tempo, sua própria natureza.

Um conceito fundamental definido pelo filósofo trata-se do que chama de força de trabalho, referindo-se à capacidade de o homem produzir mercadorias e serviços que são exigidos pelo capital. Dentro desse sistema, o trabalhador vende o seu serviço, ou seja, por ter sido expropriado, não tem mais nada, a não ser a sua força de trabalho, que é vendida como se fosse uma mercadoria e, nesse sentido, marxista, o trabalhador transforma-se em mercadoria.

Marx explica que o uso da força de trabalho é o próprio trabalho. O comprador dessa força, sendo o empregador, é quem a consumirá, fazendo com que o vendedor trabalhe. $O$ vendedor é aquele que oferecerá o seu serviço ou mercadoria, sendo o trabalhador contratado para o fazer, para ser uma extensão da máquina.

Ao efetuar-se uma linha histórica para a compreensão de como se deu a inserção da Psicologia do Trabalho, no campo fabril, é necessário o entendimento de como ocorreram as transformações no mundo do trabalho desde o final do século XIX, pois a Psicologia não foca na maquinaria, e sim nas relações humanas daqueles que trabalham e que são compreendidos pela Psicologia como seres pensantes.

A sociedade industrial foi a disparadora para a obtenção de saberes sobre o trabalho. A Psicologia se interessou por esse campo, tendo como objeto de estudo os fenômenos e processos organizacionais enquanto um fazer humano.

Conforme Leão (2012), na Revolução Industrial que ocorreu em 1760, no mundo ocidental, notadamente na Inglaterra, os saberes e afazeres de modo artesanal e de ofícios foram sendo substituidos por fábricas de manufaturas, utilizando-se de trabalhadores sem qualificação; de modo que os trabalhadores da Zona Rural, que já não tinham ocupação, migraram para as cidades. A sociedade foi mudando profundamente em seus hábitos, costumes $\mathrm{e}$ modos de trabalhar.

Os trabalhadores das fábricas executavam tarefas simples, de maneira mecânica e dividida. Não tinham direitos trabalhistas, trabalhavam cumprindo metas até a exaustão e em muitas vezes em condições de trabalho insalubres. Dessa forma, as condições de vida dos trabalhadores capitalistas tornaram-se extremamente precárias. Nesse cenário, nos Estados Unidos e na Europa surgiram as práticas e intervenções sobre os problemas que ocorriam no campo industrial. As pesquisas e experiências iniciais da Psicologia nessa área surgiram nas primeiras décadas do século XX, com o objetivo de solucionar os problemas econômicos de alguns determinados locais, tais como fábricas, escolas, prisões, indústrias, entre outros. "O objetivo dessa Psicologia Econômica era conseguir o melhor homem possível, o melhor trabalho possivel, o melhor resultado possivel" (LEÃO, 2012, p. 294).

Nesse período, a Psicologia Experimental desenvolvia pesquisas que recriavam situações cotidianas em laboratórios a fim de predizer os comportamentos e entender as variáveis dos mesmos. Tais situações tratavam-se de problemas relacionados às indústrias e aos trabalhadores como, por exemplo "[...] a jornada de trabalho, ocorrência de acidentes, fadiga, processos mentais entre pilotos de trem, serviços de navegação, entre outras categorias" (LEÃO, 2012, p. 294).

A Psicologia utilizava-se de testes para verificar e analisar questões individuais e cognitivas, tais como entender as habilidades de cada funcionário, avaliar os processos mentais - atenção, memória, tomada de decisão, julgamento e outros -, de modo que os resultados contribuíssem para as indústrias a fim de aumentar a capacidade de produção e da eficácia da força de trabalho, sustentando, assim, o capital. 
De acordo com Braverman (1981), na Era Clássica a organização no trabalho era fundamentada no taylorismo, um modelo de produção pautado na divisão do trabalho, uma administracão com ênfase no controle das tarefas, dando o poder de comando para a gerência, retirando, assim, os direitos dos trabalhadores em tomar decisões sobre os seus próprios fazeres. Não podemos afirmar que Frederick W. Taylor criou algo novo, pois já se conhecia a obra de Babbage, sobre a Administração Científica, entretanto, podemos dizer que Taylor (1851) criou um método científico e o implantou na fábrica, mostrando em resultados concretos o aumento da produtividade, da eficiência e eficácia, apontando as melhores formas de executar tarefas, propondo, assim, estratégias para aumentar o rendimento da força de trabalho e diminuir o desgaste do trabalhador. Tais estratégias voltavam-se para a seleção e orientação dos trabalhadores.

No Brasil, de acordo com Carvalho (1999), conforme a industrialização tornou-se a forma de economia prevalente, houve a necessidade da inserção de uma psicologia do trabalho para treinar orientadores aptos para as indústrias. No País, a Psicologia como Ciência e profissão foi consolidada em 1920. Foi somente nesse ano que passaram a se preocupar com esse tema, devido à ascensão dos programas psiquiátricos.

De acordo com Carvalho (1999), a Psicologia do Trabalho - conhecida na sua origem como Psicologia Industrial - servia para tratar o indivíduo como uma máquina, estimulando cada vez mais a sua produtividade, com discursos de controle e submissão, para que funcionasse da melhor maneira possível. Isso era realizado através de testes psicológicos que fariam uma triagem de quem estava ou não apto. Há três tipos de operários:

a) o tipo feliz, perfeitamente ajustado ao meio e com excelente capacidade de trabalho; b) o tipo médio, cujas deficiências adaptativas se traduzem por inquietacão e sentimento de infelicidade; c) o tipo claudicante ou falho, que acaba pela doença ou pela rebeldia. (LOPES, $1930 \mathrm{~b}$ apud LEÃO, 2012)
Em seguida, encontraram-se as primeiras consequências do processo de trabalho na saúde mental dos trabalhadores, sendo essas reações psicopatológicas decorrentes das condições de trabalho.

Em 1926 e até 1931, nos Estados Unidos, Elton Mayo atuou com a sua equipe do Departamento de Psicologia da Universidade de Harvard, realizando experimentos na empresa Western Electric, na Cidade de Chicago, em Hawthorne. Nesse período, em seus experimentos na fábrica, com os operários e operárias, descobriu que errara em suas premissas, sendo que uma das quais dava conta de que os testes psicológicos para montar um perfil de trabalhador não surtiram o efeito esperado - por exemplo, de que não se podia prever o comportamento de um trabalhador sem antes saber como era influenciado pelo grupo de trabalho.

Outra descoberta empírica de Mayo desmoronou a sua premissa de que a motivação era intrínseca e individual, concluindo que "[...] as motivações dos trabalhadores não podiam ser compreendidas numa base puramente individual, e que a chave de seu comportamento reside nos grupos sociais da fábrica", tal como afirma Braverman (1981, p. 128). Assim, a finalidade da Psicologia e Sociologia Industrial, naquele tempo, consistia em conhecer e compreender o comportamento do indivíduo e a motivação para o trabalho e, a partir disso, ajustar e manipular o trabalhador para que fosse mais eficaz, atendendo, assim aos interesses patronais.

A Psicologia, portanto, foi inserida no Brasil de modo a intervir nas relações entre trabalhadores e indústrias, para normalizá-los, discipliná-los e torná-los homogêneos. Essa forma de Psicologia Psicotécnica que permeava as relações de trabalho durou enquanto hegemônica até 1960. A partir disso, foram surgindo novas concepções focadas na saúde do trabalhador.

De acordo com Sato (2003), a Psicologia Organizacional foi criada para alinhar-se aos 
interesses gerenciais e ao capital, dando-se em um campo empresarial. Já a Psicologia Social do Trabalho foi criada com foco nas relações e vivências dos trabalhadores. São campos de pesquisa e atuação totalmente opostos entre si.

De acordo com Spink (1996), Münstenberg, em 1912, foi o primeiro a escrever de forma sistemática sobre a Psicologia no Trabalho; acreditava que a industrialização só traria benefícios para o desenvolvimento econômico e social, porém, o mesmo não levava em conta como isso poderia interferir na sociedade. E de acordo com Braverman (1981), Münstenberg acreditava que a Psicologia serviria para propósitos como encontrar trabalhadores com qualidades mentais que os tornariam altamente aptos para desenvolver as suas funções, verificando como explorar de modo mais satisfatório as produções de trabalho de cada um e analisar de que forma influenciar as mentes para atingir o patamar desejado no mundo dos negócios. Nesse sentido, Spink (1996) explica que a Psicologia contribuía para a alienação do trabalhador para que este se mantivesse em subordinação ao capital.

A Psicologia se vinculou ao mundo do trabalho, portanto, para atender aos interesses capitalistas, como já foi colocado aqui.

A Psicologia Social surgiu para modificar o objeto de trabalho até então focalizado pela Psicologia dentro das organizações. Esse campo se baseou na ideia de que apesar de o trabalho ter modificado as suas configurações, a relação entre o empregador e os trabalhadores se mantém sustentada pelo mesmo modelo. A Psicologia Social, portanto, articula a Psicologia e o marxismo, visando à saúde dos trabalhadores.

Sua ênfase estava em redescobrir a experiência dos trabalhadores para a compreensão e mudança das nocividades do ambiente laboral. É uma psicologia que convoca os trabalhadores como agentes de transformação e dá centralidade à sua subjetividade no processo de avaliação dos riscos do trabalho. (LEÃO, 2012, p. 298)
Essa abordagem da Psicologia Social trata dos seguintes assuntos: relações de gênero; trabalho infantil; os impactos que o desemprego gera; influências do meio organizacional na saúde mental dos trabalhadores; relações entre trabalho e economia; identidade e trabalho; riscos sociais; acidentes de trabalho; sofrimento psicossocial dos trabalhadores.

\begin{abstract}
Martin-Baró (1989, apud COUTINHO; FURTADO; RAITZ, 2015, p. 4) discute dois enfoques psicológicos do trabalho: individualista e sistêmico [...] o enfoque individualista explica os problemas que caracterizam nossas situações de trabalho como decorrentes de dificuldades pessoais. Já o enfoque sistêmico, centrado nas organizações sem considerar suas conexões com a sociedade na qual se inserem, compreende as dificuldades de nosso cotidiano de trabalho como consequências do atraso tecnológico ou mesmo de problemas culturais.
\end{abstract}

Martin-Baró (1989) também argumenta que a Psicologia Política deve abranger os setores marginalizados, explorados, discriminados como sujeitos - e não objetos.

Sato (2003) afirma que a Psicologia Social do Trabalho investiga questões subjetivas ligadas ao trabalho a partir do olhar dos trabalhadores, pois esse campo entende que o trabalho se constitui e integra espaços de construção de identidades, socialização e transformação.

\section{Clima Organizacional}

De acordo com Chiavenato (2002), o clima organizacional refere-se à qualidade do ambiente organizacional, na percepção dos trabalhadores. A partir da avaliação do ambiente e das necessidades dos trabalhadores e participantes da equipe gerencial, a Psicologia visa o equilíbrio emocional dos indivíduos, identificando a demanda do local e intervindo sobre a qual. 
As empresas, organizações e instituições devem sempre optar por um clima favorável, visando à saúde mental de seus funcionários e também à satisfação das necessidades que possuem. A motivação que esses trabalhadores têm está ligada ao clima ser ou não ser favorável. É comum que muitas instituições façam pesquisas de clima organizacional para entender se está favorável e se os funcionários se sentem satisfeitos ou insatisfeitos, podendo-se, assim, criar ambientes visando à qualidade da saúde física e psicológica dos funcionários. Gil (2011) afirma que os funcionários agirão de acordo com a forma com a qual se sentem motivados; e essa motivação acontecerá conforme sentem a necessidade de se atingir um objetivo.

O estilo de liderança da gerência de uma instituição também influencia no clima. De acordo com Robbins (2011), a liderança é a capacidade de inspirar e influenciar pessoas através de atitudes e ideias, com o intuito de atingir um objetivo.

Robbins (2011, p. 285) trata de um estilo de liderança contemporâneo conhecido como liderança transformacional e transacional. O líder transacional "[...] conduz ou motiva seus seguidores na direção das metas estabelecidas por meio do esclarecimento dos papéis e das exigências das tarefas". O líder transformacional "[...] inspira seus seguidores a transcender seus próprios interesses para o bem da organização". Robbins (2011) informa que ambas as lideranças se completam. As formas de pensar dos gerentes de uma instituição influenciarão os funcionários e seus comportamentos. É, portanto, importante no exercício de uma liderança conseguir formas de incentivar os trabalhadores a não atuarem somente pelo incentivo salarial ou apenas quando são supervisionados. O bom líder, nessa perspectiva, é aquele que integra os trabalhadores nas decisões tomadas pela gerência, no planejamento do funcionamento da instituição, abrindo espaço para que os trabalhadores explorem as suas criatividades e desenvolvam as próprias potencialidades.

Gil (2011) ao tratar de motivação e de acordo com Herzberg, assinala que na motivação humana influem dois fatores que fazem com que os trabalhadores sintam-se satisfeitos ou não, que se constituem nos fatores higiênicos; o outro fator é motivacional, levando-se em conta que para Herzberg trabalhar é uma dádiva divina, dado que o homem, por natureza, gosta de trabalhar.

Os fatores higiênicos seriam os estímulos extrínsecos, positivos quanto às condições físicas de trabalho, o salário, os incentivos sociais, recreativos, as políticas, normas e regras da instituição, condições físicas de segurança e a garantia que o trabalhador possui de sua permanência na organização.

Já os fatores motivacionais seriam intrínsecos, o sentimento de responsabilidade pela função que executa, sentir-se reconhecido, realizado, alcançar os objetivos relacionados às funções que exerce, autonomia e liberdade na execução de suas funções.

Outra teoria de motivação, que foi o modelo identificado, é o comportamental, na qual o comportamento dos funcionários dependerá das consequências que tal comportamento tiver. Se forem favoráveis, o funcionário entenderá que acertou e repetirá; se não, tenderá a extinguir tal ação e evitará errar novamente.

\section{Casas-abrigo}

De acordo com a Secretaria de Políticas para as Mulheres (BRASIL, 2011), o abrigamento traduz-se em serviços e programas oferecidos pela política e destinados a diversos públicos.

No trabalho em questão, entretanto, o conceito de abrigamento será restrito ao público feminino em situação de violência e vulnerabilidade, que estão sob ameaça e precisam de proteção. Assim lhes é na modalidade institucional, garantido um acesso a locais seguros, geralmente sigilosos. Os serviços prestados constam de uma rede de atendimento que inclui acolhimento e orientações jurídicas, assistenciais e psicológicas, além de poder proporcionar aos vulneráveis um alojamento por tempo indeterminado nas casas-abrigo. 
Segundo Coutinho e Sani (2010), as casas-abrigo são equipamentos que respondem às necessidades de mulheres com ou sem filhos, vítimas de situação vulnerável, com violência ou não, que se veem obrigadas ao abandono de seus lares e, muitas vezes, das próprias famílias, por não possuírem recursos, ou por estarem em situação de perigo de morte. Dessa forma, tais instituições oferecem acolhimento e seguranca, promovendo a reorganização de um novo projeto e sentido de vida.

As diretrizes nacionais de abrigamento são as seguintes:

Igualdade e respeito à diversidade - mulheres e homens são iguais em seus direitos. A promoção da igualdade implica o respeito à diversidade cultural, étnica, racial, inserção social, situação econômica e regional, assim como os diferentes momentos da vida das mulheres; Autonomia das mulheres - o poder de decisão sobre suas vidas e corpos deve ser assegurado às mulheres, assim como as condições de influenciar os acontecimentos em sua comunidade e seu país; Laicidade do Estado - as políticas públicas voltadas para as mulheres devem ser formuladas e implementadas independentemente de princípios religiosos, de forma a assegurar os direitos consagrados na Constituição Federal e nos instrumentos e acordos internacionais assinados pelo Brasil; Universalidade das políticas - as políticas públicas devem garantir, em sua implementação, o acesso aos direitos sociais, políticos, econômicos, culturais e ambientais para todas as mulheres; Justiça social - a redistribuição dos recursos e riquezas produzidas pela sociedade e a superação da desigualdade social, que atinge de maneira significativa às mulheres, devem ser assegurados; Participação e controle social - o debate e a participação das mulheres na formulação, implementação, avaliação e controle social das políticas públicas devem ser garantidos e ratificados pelo Estado brasileiro, como medida de proteção aos direitos humanos das mulheres e meninas. (BRASIL, 2011, p. 17-18)

\section{Proposta e intervenção}

Após efetuar o levantamento de necessidades institucionais, emergiu a possibilidade de intervir junto à equipe de funcionários que atuam diretamente com as conviventes da instituição. Percebeu-se comportamentos conflituosos entre as duas equipes de trabalho que atuam em escalas diferentes, promovendo algumas situações de descompasso nas rotinas de trabalho.

A equipe de funcionários é composta de agentes operacionais e orientadores socioeducativos, sendo os primeiros responsáveis pelo cuidado com o local, realizando a limpeza, fazendo reparos e a manutenção predial. E os segundos são os responsáveis pelos cuidados para com as mulheres conviventes, instruindo-as no atendimento assertivo das regras, normas, valores, direitos e deveres a serem cumpridos no dia a dia. A equipe técnica é composta pela gerente, psicóloga e assistente social.

A gerente foi admitida recentemente e adotou uma liderança centralizadora e diretiva, assumindo uma posição de autoridade e tomando decisões que os funcionários não estavam acostumados. Efetuou algumas admissões para sentir-se mais apoiada pelos novatos e demitiu alguns poucos funcionários que estavam defensivos e resistentes às novas diretivas. Dessa forma, notavam-se duas equipes.

Para conhecer melhor esse contexto, a intervenção constou de duas partes: a primeira etapa se relacionou ao levantamento das necessidades, com a observação do local, entrevistas individuais com as equipes de trabalho, equipe técnica e gerência. Foram efetuadas entrevistas individuais, semiestruturadas com roteiro focal, versando sobre atividades exercidas no trabalho, como a pessoa se sentia em sua função profissional, o que poderia melhorar em suas atividades e como ocorriam as relações de trabalho.

A segunda parte da intervenção consistiu de atividades coletivas, com exercícios de dinâmica de grupo contemplando os funcionários dos dois plantões. Os participantes foram seis agentes operacionais e seis orientadores socioeducativos. 
Os exercícios de dinâmica de grupo tiveram a finalidade de auxiliar os participantes a identificarem as próprias potencialidades dentro da instituição, conhecendo os seus pontos fortes e fracos, possibilitando, dessa forma, maior compreensão de suas atividades e responsabilidades individuais e de grupo.

As primeiras dinâmicas de grupo criaram uma relação de confiança entre os participantes e as estagiárias de Psicologia, visando à integração dos grupos e livre expressão sobre as atividades no trabalho.

Nas demais dinâmicas de grupo foram abordados os temas de autopercepção, criatividade, empatia, autoestima e resiliência. Em todas as dinâmicas o tema espírito de equipe e assertividade no trabalho era abordado.

Como ilustração, cita-se a dinâmica de grupo conhecida como jogo das virtudes, na qual os participantes ampliaram a percepção e o conhecimento de si e de outrem. Os exercícios coletivos auxiliaram os envolvidos à receptividade a críticas, elogios e também à identificaç̃̃o, nas discussões, de suas potencialidades.

\section{Análise e resultados}

Para compreender e apreender as carências e demandas do local, decidiu-se por intervenção junto às duas equipes de trabalho que apresentaram fragilidades nas habilidades sociais no ambiente profissional.

Com relação às duas equipes de trabalho, foi possível verificar que existiam dois polos de opiniões no que se refere ao trabalho executado na instituição, no qual um dos quais concordava totalmente com o modo de funcionamento; e o outro discordava diametralmente.

O fator da discórdia devia-se ao fato de que a instituição passara recentemente por diversas gestões, cada qual apresentando uma proposta específica; na mudança de gerência da última para a atual houve demissões. Alguns dos funcionários que ficaram e já estavam acostumados com a organização do sistema antigo, acabaram encontrando certa dificuldade na adaptação à nova realidade, ocasionando algumas críticas à nova gerência.

Os funcionários com melhor adesão ao trabalho eram novatos na instituição, assim como alguns profissionais veteranos também se adaptaram de maneira tranquila. Ressalta-se também que alguns foram trazidos e indicados pela própria gerente atual, endossando adesão à nova gestão.

Procuramos investigar a preparação dos funcionários para trabalhar com o público da instituição - mulheres em situação de vulnerabilidade - e a motivação dos mesmos. É de muita importância que o clima organizacional da instituição, na percepção dos trabalhadores, seja favorável às suas necessidades, visando ao equilíbrio emocional de todos, tanto individual quanto coletivamente.

A motivação dos funcionários está ligada diretamente ao clima organizacional ser ou não favorável, pois sempre agirão conforme sentirem algum propósito no que fazem em seus ambientes de trabalho.

Considerando o atual cenário político e trabalhista brasileiro, muitos dos trabalhadores do País visam como prioridade os próprios sustentos, independentemente de encontrarem um propósito no trabalho que executam. Foi possível identificar essa questão em muitas das falas; logo, faz-se necessário que seja encontrado um propósito tanto individual quanto coletivo.

O principal influenciador na motivação e maneira de se trabalhar em uma organização é o estilo de liderança da gerência, percebido aqui - neste caso, pelos funcionários descontentes - como autoritário. Por outro lado, ao se efetuar uma análise da gerência, mostrou-se que a liderança da gerente se apresenta assertiva, voltada às necessidades das conviventes e para o cumprimento de metas de trabalho. O seu estilo é transformacional e transacional, no qual a líder conduz os funcionários na direção de metas a serem realizadas por meio do esclarecimento dos papéis e das funções de cada um, assim como das exigências do que deve ser cumprido. 
Um bom líder age de modo transformacional, inspirando e motivando os funcionários a irem além de seus interesses próprios a fim de alcançar o que seria melhor para a instituição. Pelo que foi analisado nos relatos, tudo indica que a gerente é diretiva, mas não é coercitiva, o local e as situações de trabalho é que impõem uma liderança forte, e isto não é bem recebido por todos os funcionários.

Conforme foi relatado, as equipes de funcionários e técnica reúnem-se mensalmente para discutir o andamento das atividades realizadas no centro. De acordo com a equipe técnica, esse é um espaço para que todos façam sugestões de melhorias no local. Esse momento deve ser explorado sempre que possível, para que os trabalhadores sejam integrados nas decisões tomadas e também possam explorar as suas criatividades, pois somente assim se enxergarão como agentes transformadores. Dessa forma, recomendou-se à gerência promover reuniões de entrosamento e esclarecimento sobre as responsabilidades do papel de cada um na instituição.

As duas principais motivações identificadas nos funcionários do CAE são as correspondentes aos fatores higiênicos - condições físicas de trabalho, salário, condições físicas de segurança e a garantia que possuem de sua permanência no local - e aos comportamentais, nos quais aprendem baseando-se nas consequências de seus atos, ou seja, se agirem de determinada forma e obterem consequências positivas, os atos se repetirão; se as consequências forem negativas, não se repetirão.

Considerando que trabalhamos com os funcionários tanto individual quanto coletivamente, notamos distinções nos seus discursos e no modo de se comportarem, principalmente quando inseridos em um grupo, manifestando-se a questão da familiaridade e amizade que há - ou não - na equipe.

No plantão que intitularemos de 1, houve menor adesão por parte dos funcionários para realizar as duas dinâmicas em grupo. Tanto na primeira quanto na segunda dinâmica, o grupo não se mostrou sólido ou entusiasmado, tampouco enxergou a dinâmica com seriedade.

Quanto ao plantão que intitularemos de 2, o clima foi totalmente oposto: houve aderência nas duas dinâmicas, nas quais o grupo mostrou-se fortalecido e unido. Por diversas vezes os funcionários diziam que eram como uma família e um quebra-cabeças onde todas as peças se encaixavam. A motivação no plantão 2 foi trabalhada de maneira satisfatória e todos enxergaram-se como indivíduos portadores de diversos pontos fortes, virtudes e qualidades.

O que pôde ser analisado é que quando uma equipe se encontra unida e está ciente de suas virtudes, a motivação acaba sendo uma consequência que ocorre naturalmente. Em muitos momentos quando os funcionários eram convidados a pensar sobre os seus próprios pontos fortes e as maneiras de melhorar os aspectos fracos, demonstravam surpresa por até então não terem refletido sobre si.

Muitos dos pontos fracos foram de cunho pessoal, porém, interferiam no trabalho, de modo que por meio das discussões realizadas ao final das atividades os funcionários eram colocados para se autoenfrentar.

Sobre as atividades em que os funcionários precisaram falar sobre virtudes de seus colegas, por diversas vezes demonstraram-se surpreendidos e admirados ao ouvirem a forma como os outros os enxergavam.

No processo de intervenção, apesar dos esforços dispendidos com a integração dos participantes, as resistências de mudança de comportamentos divergentes e conflituosos não foram quebradas, havendo a necessidade de um desenvolvimento contínuo para que se possa vislumbrar a coesão dos dois grupos.

Quanto às potencialidades que despontaram no processo de intervenção, observou-se que os comportamentos virtuosos das duas equipes mostraram empatia, solidariedade com os seus colegas de turno e com as conviventes. Os dois plantões evidenciaram convergência 
e vocação para a atuação junto a pessoas em vulnerabilidade social.

Houve melhora na convivência e ampliação da percepção e o conhecimento de si e do outro. Fortaleceram-se ao ouvir críticas e se surpreenderam ao receberem elogios dos colegas, e também a identificarem, nas discussões, as suas potencialidades. A expectativa aqui é que se houver continuidade de desenvolvimento das equipes, os resultados serão promissores.

\section{Considerações finais}

Passamos grande parte de nossas vidas trabalhando, e é nesse ambiente que ocorre a maioria das relações interpessoais, que para serem bem-sucedidas necessitam de habilidades sociais, as quais envolvem engajamento no intercâmbio verbal e na interação.

Nesse sentido, a intervenção realizada na instituição de acolhimento para mulheres em vulnerabilidade social visou promover a conscientização da potencialidade de cada funcionário, reforçando os seus pontos fortes, reconhecendo os seus aspectos fracos, com o intuito de desenvolver uma reflexão acerca de como melhorar, intensificando habilidades pessoais, assertivas e cordiais.

Foram efetuadas entrevistas com os funcionários, individualmente e em atividades coletivas em situações de dinâmicas de grupo. Foi possível verificar que a maioria dos profissionais veteranos ainda tem apego e aderência para com a gestão anterior e, por isso, questionam e criticam diretivas e regras, colocando-se na posição vitimizada e resistindo às mudanças. Por sua vez, os funcionários ingressantes na nova gestão se mostraram unidos, com espírito de equipe, identificando-se com as propostas da gerência. Desse modo, percebeu-se a polarização de opiniões no que se refere ao trabalho executado na instituição, no qual um dos lados concorda totalmente com o modo de funcionamento, e o outro discorda diametralmente.

Nesse sentido, na intervenção trabalhou-se com a motivação, o aumento da autoestima, a resiliência, a empatia e aceitação dialética de ideias contrárias.

Os resultados mostraram duas equipes com perfis específicos: a primeira apresentou resistência e a segunda equipe se mostrou estruturada, disposta e participativa para com as propostas apresentadas. Entretanto, pudemos concluir que todos são, de certa maneira, agentes transformadores, bastando que cada um encontre formas e recursos para trabalhar as próprias potencialidades, desde que possibilitando-se aos funcionários um aprendizado e desenvolvimento contínuo voltado às habilidades sociais.

Por último, salienta-se que os objetivos propostos foram parcialmente alcançados, pois não houve condições de maior avanço, por limitação do cronograma do estágio e da resistência humana em mudar e aceitar o novo como uma perspectiva de crescimento.

\section{Referências}

BRASIL. Secretaria de Políticas para as Mulheres. Diretrizes nacionais para o abrigamento. Brasília, DF, 2011. Disponível em: <https://www12. senado.leg.br/institucional/omv/entenda -a-violencia/pdfs/diretrizes-nacionais-parao-abrigamento-de-mulheres-em-situacao-de -risco-e-de-violencia>. Acesso em: 10 out. 2018.

BRAVERMAN, H. Trabalho e capital monopolista: a degradação do trabalho no século XX. 3. ed. Rio de Janeiro: Zahar Editores, 1981.

CARVALHO, A. M. T. Trabalho e higiene mental: processo de produção discursiva do campo no Brasil. História Ciência e Saúde, v. 6, n. 1, p. 133-156, 1999. Disponível em: <http://www. scielo.br/scielo.php?script=sci_arttext\&pi $d=S 010459701999000200007 \& \operatorname{lng}=e n \& n r m=i$ so\&tlng=pt>. Acesso em: 8 out. 2018. 
CHIAVENATO, I. Recursos humanos. 7. ed. São Paulo: Atlas, 2002.

COUTINHO, M.; FURTADO, O.; RAITZ, T. (Org.). Psicologia social e trabalho: perspectivas críticas. v. 1. Florianópolis, SC: Abrapso; Edições do Bosque, 2015.

COUTINHO, M.; SANI, A. Casa-abrigo: solução ou problema? Psic. Teoria e Pesquisa, v. 26, n. 4, p. 633-641, 2010. Disponível em: <http://www. scielo.br/pdf/ptp/v26n4/07.pdf> Acesso em: 10 out. 2018.

GIL, A. C. Gestão de pessoas: enfoque nos papéis profissionais. São Paulo: Atlas, 2011.

LEÃO, L. Psicologia do trabalho: aspectos históricos, abordagens e desafios atuais. Ecos Estudos Contemporâneos da Subjetividade, v. 2, n. 2, 2012. Disponível em: <http://www.perio dicoshumanas.uff.br/ecos/article/viewFi le/1008/722>. Acesso em: 8 out. 2018.
MARTÍN-BARÓ, I. Sistema, grupo y poder. Psicología social desde Centroamérica II. San Salvador: UCA, 1989. (Col. Textos Universitários; 10). MARX, K. O capital. São Paulo: Boitempo, 2011. ROBBINS, S. Comportamento organizacional: teoria e prática no contexto brasileiro. 14. ed. São Paulo: Pearson Prentice Hall, 2011.

SATO, L. Psicologia, saúde e trabalho: distintas construções dos objetos "trabalho" e "organizações". São Paulo: Casa do Psicólogo, 2003.

SPINK, P. K. Organização como fenômeno psicossocial: notas para uma redefinição da Psicologia do Trabalho. Psicologia \& Sociedade, v. 8, n. 1, p. 174-192, jan./jun. 1996. Disponível em: <https:// edisciplinas.usp.br/pluginfile.php $/ 594745 / \mathrm{mod}$ resource/content/1/A\%20organiza\%C3\%A7\% C3\%A3०\%20como\%2Ofen\%C3\%B4meno\%20 psicossocial.pdf>. Acesso em: 10 out. 2010. 
